\title{
Medo e ansiedade de estudantes de odontologia durante a segunda onda da pandemia de COVID-19
}

\author{
Fear and anxiety of dentistry students during the second wave of the COVID-19 pandemic \\ Miedo y ansiedad de estudiantes de odontología durante la segunda onda de la pandemia COVID-
}

Karlos Eduardo Rodrigues Lima ORCID: https://orcid.org/0000-0003-3127-9772 Centro Universitário Católica de Quixadá, Brasil E-mail: karlosed99@gmail.com

Victoria Caroline da Silva

ORCID: https://orcid.org/0000-0002-7091-6749 Centro Universitário Católica de Quixadá, Brasil E-mail: vicctoriacsilva@outlook.com

Isadora Oliveira dos Santos ORCID: https://orcid.org/0000-0003-1766-8464 Centro Universitário Católica de Quixadá, Brasil

E-mail: oisadora205@gmail.com

Maria Joane Coelho de Sousa ORCID: https://orcid.org/0000-0001-9822-1554 Centro Universitário Católica de Quixadá, Brasil

E-mail: joane.sousa23@gmail.com

Pedro Henrique Chaves Isaias ORCID: https://orcid.org/0000-0003-4399-1302 Universidade Federal do Ceará, Brasil E-mail:ph.isaias@yahoo.com

Talita Arrais Daniel Mendes ORCID: https://orcid.org/0000-0003-3519-3618 Universidade Federal do Ceará, Brasil E-mail: talita_arrais@hotmail.com

Érika Matias Pinto Dinelly ORCID: https://orcid.org/0000-0003-2786-3132 Centro Universitário Católica de Quixadá, Brasil E-mail: erikamatias@unicatolicaquixada.edu.br

Ana Karine Macedo Teixeira

ORCID: https://orcid.org/0000-0001-5923-1813

Universidade Federal do Ceará, Brasil

E-mail: anakarinemt@hotmail.com

Cosmo Helder Ferreira da Silva ORCID: https://orcid.org/0000-0002-7517-2662 Centro Universitário Católica de Quixadá, Brasil E-mail: helderferreira@ unicatolicaquixada.edu.br

Raul Anderson Domingues Alves da Silva ORCID: https://orcid.org/0000-0002-7625-3595 Universidade Federal do Ceará, Brasil

E-mail: raulalves@unicatolicaquixada.edu.br

\section{Resumo}

A assistência em saúde bucal é considerada como uma prática de risco para a transmissão e contaminação pelo vírus da COVID-19, principalmente devido à geração de aerossóis e a proximidade com o paciente. O objetivo deste trabalho foi investigar a percepção de estudantes de odontologia quanto ao medo e à ansiedade em relação ao manejo de pacientes e o risco de infecção no contexto da pandemia da COVID-19. Trata-se de um estudo transversal realizado com 167 alunos de graduação em odontologia de um centro universitário no interior do Ceará. A coleta de dados foi realizada entre março e abril de 2021 através do preenchimento de um questionário on-line subdividido em: dados sociodemográficos, avaliação do medo e insegurança quanto à assistência odontológica e avaliação dos sintomas de ansiedade, por meio do Inventário de Ansiedade de Beck. Os dados foram então analisados no Statistical Package for the Social Sciences (SPSS) 22.0, considerando um nível de confiança de $95 \%$ e significância de p<0,05. A média da escala de Beck de ansiedade foi de 18,84 $( \pm 12,88)$ e $61,1 \%$ dos discentes relataram sintomas mínimos/leves de ansiedade. A presença de sintomas mínimos/leves esteve relacionada à posse de uma crença/religião $(\mathrm{p}=0,039)$, 
ausência de medo no atendimento a pacientes com suspeita de COVID-19 ( $\mathrm{p}=0,003$ ), ausência de insegurança no retorno às práticas clínicas $(\mathrm{p}=0,008)$. Em suma, a maioria dos discentes apresentou sintomas mínimos/leves de ansiedade, o que se associou a um menor medo e insegurança na realização de práticas clínicas e à presença de uma religião.

Palavras-chave: Medo; Ansiedade; Infecções por coronavírus; Estudantes de odontologia; Ensino.

\begin{abstract}
Oral health care is considered a risky practice for COVID-19, mainly due to the generation of aerosols and proximity to the patient. Because of this, dental practice was changed in the face of the pandemic. Thus, the objective was to investigate the perceptions of dentistry students regarding fear and anxiety in relation to patient management and the risk of infection in the context of the COVID-19 pandemic. This is a cross-sectional study carried out with 167 undergraduate dentistry students from a university center in the interior of Ceará. Data collection was carried out between March and April 2021 by completing an online questionnaire subdivided into: sociodemographic data, assessment of fear and insecurity regarding dental care and assessment of anxiety symptoms, through the Anxiety Inventory of Beck. Data were then analyzed using the Statistical Package for Social Sciences (SPSS) 22.0, considering a $95 \%$ confidence level and significance of $\mathrm{p}<0.05$. The average of the Beck anxiety scale was 18.84 $( \pm 12.88)$ and $61.1 \%$ of the students reported minimal/mild symptoms of anxiety. The presence of $\mathrm{minimal} / \mathrm{mild}$ symptoms was related to possession of a belief/religion $(\mathrm{p}=0.039)$, lack of fear in caring for patients with suspected COVID-19 ( $p=0.003)$, absence of insecurity in returning to clinical practices $(p=0.008)$. In short, most students had minimal/mild symptoms of anxiety, which was associated with less fear and insecurity in performing clinical practices and the presence of a religion.
\end{abstract}

Keywords: Fear; Anxiety; Coronavirus infections; Dentistry students; Teaching.

\title{
Resumen
}

El cuidado de la salud bucal se considera una práctica de riesgo para el COVID-19, principalmente debido a la generación de aerosoles y la proximidad al paciente. Debido a esto, la práctica dental cambió ante la pandemia. Así, el objetivo fue investigar las percepciones de los estudiantes de odontología sobre el miedo y la ansiedad en relación al manejo del paciente y el riesgo de infección en el contexto de la pandemia COVID-19. Se trata de un estudio transversal realizado con 167 estudiantes de licenciatura en Odontología de un centro universitario del interior de Ceará. La recogida de datos se realizó entre marzo y abril de 2021 mediante la cumplimentación de un cuestionario online subdividido en: datos sociodemográficos, valoración del miedo e inseguridad en el cuidado dental y valoración de los síntomas de ansiedad, a través del Inventario de Ansiedad de Beck. Luego, los datos se analizaron utilizando el Paquete Estadístico para Ciencias Sociales (SPSS) 22.0, considerando un nivel de confianza del $95 \%$ y un nivel de significancia de $\mathrm{p}<0.05$. El promedio de la escala de ansiedad de Beck fue $18,84( \pm 12,88)$ y el $61,1 \%$ de los estudiantes refirió síntomas mínimos / leves de ansiedad. La presencia de síntomas mínimos / leves se relacionó con la posesión de una creencia / religión $(\mathrm{p}=0,039)$, falta de miedo en el cuidado de pacientes con sospecha de COVID-19 $(\mathrm{p}=0,003)$, ausencia de inseguridad en el retorno a la práctica clínica $(\mathrm{p}=0,008)$. En resumen, la mayoría de los estudiantes presentaban síntomas mínimos / leves de ansiedad, los cuales se asociaban con menos miedo e inseguridad en la realización de prácticas clínicas y la presencia de una religión.

Palabras clave: Miedo; Ansiedad; Infecciones por coronavirus; Estudiantes de Odontología; Ensenãnza.

\section{Introdução}

Desde dezembro de 2019, diversos casos de pneumonia viral começaram a surgir na Ásia, mais especificamente. Os primeiros casos estavam relacionados a pacientes que estiveram em um mercado de frutos do mar na cidade de Wuhan, na China (Xu et al., 2020). Foi então descoberto que tal condição patológica tratava-se de uma nova doença, a hoje denominada COVID-19, causada por um novo tipo de coronavírus, classificado atualmente como SARS-CoV-2, detentor de um demasiado potencial de replicação (Lu et al., 2020).

Rapidamente, tal condição se propagou por diversas partes do mundo, sendo decretada pela Organização Mundial da Saúde (OMS) como uma pandemia em 11 de março de 2020 (Zhang \& Ma, 2020). Em pacientes sintomáticos, as manifestações da COVID-19 podem se apresentar como: febre, tosse, dispneia, congestão nasal, fadiga e outros sinais de infecções no trato respiratório, podendo progredir para um estado grave desta doença com presença de sintomas torácicos graves (Velavan \& Meyer, 2020).

Os profissionais da saúde estão bastante expostos ao risco de infecção pela COVID-19, visto que prestam assistência em saúde à população. Dentre eles, destacam-se os cirurgiões-dentistas, que por realizarem procedimento geradores de aerossóis e executarem suas ações próximos ao paciente, estão em alto risco de exposição e consequente contaminação pelo 
SARS-CoV-2 (Prado et al., 2020). Diante desta exposição constante e também pelo alto potencial de transmissão e contaminação pelo vírus, os profissionais passaram a conviver com o medo de uma possível infecção, bem como de ocasionarem a contaminação de outras pessoas em seu cotidiano (Atas \& Talos, 2020).

Devido às medidas de distanciamento social impostas pela necessidade de prevenção e redução dos números de casos da COVID-19, o ensino odontológico nas universidades foi prejudicado, visto que não há como substituir as atividades práticas por ensino remoto. Diante disso, os atendimentos clínicos tornaram-se um desafio, já que é preciso pensar na saúde e no bem estar de alunos, professores, familiares, pacientes e funcionários para que haja um processo de ensino-aprendizagem de qualidade (De Almeida et al., 2020; Elani et al., 2014).

Ademais, frente ao período pandêmico que vivenciamos, os períodos de distanciamento social associados à ausência de atividades estudantis e o consequente atraso na conclusão do curso, bem como o receio de contaminação própria ou de familiares e amigos pelo vírus, podem originar momentos de incerteza, ansiedade e estresse nos discentes (De Almeida et al., 2020; Sahu, 2020).

Avaliações sobre o medo e ansiedade entre estudantes de odontologia no atual cenário ainda é incipiente, e pode ajudar as universidades a lidar melhor com seus alunos neste período de crise e entender como as condições psicológicas de seus discentes refletem no desempenho destes durante o curso. Diante disso, o presente estudo objetivou investigar as percepções de estudantes de odontologia quanto ao medo e à ansiedade em relação ao manejo de pacientes e o risco de infecção no contexto da pandemia da COVID-19.

\section{Metodologia}

Trata-se de um estudo observacional, do tipo transversal, realizado com os alunos de graduação do curso de Odontologia do Centro Universitário Católica de Quixadá (Unicatólica). Respeitando todo os princípios éticos, esta pesquisa foi submetida ao Comitê de Ética em Pesquisa da Unicatólica, obtendo parecer de aprovação de número 4.586.067. E por se tratar de pesquisa em seres humanos, os participantes da mesma, assinaram um Termo de Consentimento Livre e Esclarecido.

Para definição da amostra, realizou-se um cálculo amostral (n= $\left[\operatorname{EDFF}^{*} N p(1-\mathrm{p})\right] /[(\mathrm{d} 2 / \mathrm{Z} 2$ 1- $\alpha / 2 *(\mathrm{~N}-1)+\mathrm{p} *(1-\mathrm{p})]$ ) no software OpenEpi considerando o número de alunos que cursavam disciplinas práticas que lidam diretamente com pacientes ( $\mathrm{n}=239$ ), por meio de dados fornecidos pela coordenação do curso de odontonlogia da Unicatólica. Considerou-se também o limite de confiança de 5\% e o efeito de desenho 1,0, onde obteve-se uma amostra mínima de 148 alunos.

O estudo incluiu os alunos do curso de graduação em odontologia da Unicatólica, devidamente matriculados no semestre 2021.1 e que participavam de pelo menos uma disciplina com assistência a pacientes. Os critérios de exclusão foram: alunos menores de 18 anos, os que tiveram a matrícula trancada ao longo do semestre e que não responderam corretamente o questionário aplicado.

A coleta de dados foi executada entre março e abril de 2021, através do preenchimento de um questionário semiestruturado e autoaplicável, on-line, enviado por e-mail e/ou pelas redes sociais (WhatsApp) para os participantes. O questionário foi composto por três partes: avaliação sociodemográfica; avaliação do medo e insegurança quanto a realização de atendimentos clínicos durante a pandemia; avaliação dos sintomas de ansiedade. A avaliação sociodemográfica foi realizada com perguntas a respeito de informações sobre sexo, idade, cor/raça, estado civil, filhos, trabalho, renda mensal familiar, religião dos participantes.

Já a segunda parte, foi composta por 7 perguntas de múltipla escolha (sim; não; não sei dizer). Foram utilizadas as perguntas traduzidas e adaptadas do questionário de Ahmed e colaboradores (2020) sobre o medo quanto ao atendimento clínico odontológico durante a pandemia. Entretanto, a fim de se adequar a realidade brasileira e por se tratar de um estudo com estudantes de odontologia, três questões do questionário foram removidas: "Do You want to Close Your Dental Practice 
until the Number of COVID-19 Cases Starts Declining?", "Are you afraid of getting quarantined if get infected?" e "Are You Anxious about the Cost of Treatment if You Get Infected?". Além disso, foram acressentadas duas perguntas sobre a insegurança quanto ao retorno das atividades clínicas.

Já o terceiro item, analisou os sintomas de ansiedade através do Inventário de Ansiedade Beck (BAI). O instrumento é composto por uma escala de auto relato que mensura através de 21 itens a intensidade dos sintomas de ansiedade sentidas na última semana pelo participante (Beck et al., 1988). Utilizou-se, no presente estudo, a versão do questionário que foi validada e traduzida para a população brasileira (Cunha, 2001). As respostas variam por uma escala do tipo likert de acordo com a intensidade em que o sintoma é sentido, variando entre: Ausente (0); Suave (1); Moderado (2); e Severo (3). Os valores das respostas são somados em um escore que pode variar entre 0 e 63, utilizado para classificar o nível de ansiedade sentido pelo participante em: mínimo (0 a 10); leve (11 a 19), moderado (20 a 30) e grave (31 a 63). Para efeitos de análise, a classificação do nível de ansiedade foi dicotomizada em: mínimo/leve e moderado/grave.

Os dados coletados foram exportados para o software Statistical Package for the Social Sciences (SPSS) 22.0, onde as análises foram realizadas considerando um nível de confiança de $95 \%$ e significância de $p<0,05$. A determinação da associação entre as variáveis independentes e as variáveis dependentes, foi realizada pelo teste de associação Qui-quadrado de Pearson e o Teste exato de Fisher.

\section{Resultados}

A amostra final foi composta por 167 alunos que responderam ao questionário e se adequaram aos critérios constituídos. O valor é superior ao cálculo amostral pré-estabelecido, tornando-se representativa para a população estudada. A amostra foi composta principalmente por estudantes do sexo feminino (73,1\%), autodeclarados negros (56,9\%), solteiros (95,2\%), que não trabalham (85,6\%), como uma renda familiar maior que 2 salários mínimos (59,3\%), e que possuíam religião (88,0\%), dos quais a maioria (76,2\%) eram católicos (Tabela 1). A média de idade dos estudantes avaliados foi de 22,11 anos, variando entre 18 e 42 anos. Já a média salarial mensal da família foi de $R \$ 2908,47$, variando entre $R \$ 400$ e $R \$ 18.000$.

Tabela 1: Dados sociodemográficos dos estudantes de odontologia da Unicatólica. Quixadá - CE, 2021.

\begin{tabular}{l|cc}
\hline \multicolumn{1}{c}{ Variáveis } & $\mathrm{n}$ & $\%$ \\
\hline Sexo & 122 & 73,1 \\
Feminino & 45 & 26,9 \\
Masculino & 72 & \\
\hline Autodeclaração da raça & 95 & 43,1 \\
Branca & & 56,9 \\
Negra & 8 & 4,8 \\
\hline Estado Civil & 159 & 95,2 \\
Casado / União Estável & & 4,2 \\
Solteiro & 7 & 95,8 \\
\hline Filhos & 160 & 14,4 \\
Sim & & 85,6 \\
Não & 24 & \\
\hline Trabalha & 143 & 40,7 \\
Sim & & 59,3 \\
Não & 68 & \\
\hline Renda & 99 & 88,0 \\
Até 2 Salários Mínimos & & 12,0 \\
Acima de 2 Salários Mínimos & 147 & \\
\hline Religião & 20 & \\
Sim & & \\
Não & & \\
\hline
\end{tabular}




\begin{tabular}{l|cc}
\hline Tipo de Religião & & \\
Católica & 112 & 76,2 \\
Protestante & 35 & 23,8 \\
\hline
\end{tabular}

Fonte: Autores.

Nas perguntas direcionadas ao medo quanto ao atendimento de pacientes no período da pandemia de COVID-19, a maioria dos alunos afirmaram que: sente medo quando escuta que as pessoas estão morrendo por COVID-19 (90,4\%); que possui medo de levar a infecção para sua família $(89,2 \%)$; que não se sente nervoso ao conversar com pacientes em lugares fechados (55,1\%); que se sente ansiosos quanto ao oferecimento de atendimento clínico à um paciente com suspeita de COVID-19 (80,2\%); e que está com medo de ser infectado por um paciente ou colega de sala (79,6\%). Cerca de 46,7\% dos alunos afirmaram que se encontram inseguros quando ao retorno das atividades práticas e, destes, a maioria $(68,4 \%)$ afirmou que o principal motivo é o medo da contaminação de COVID-19 (Tabela 2).

Tabela 2: Avaliação do medo e insegurança dos estudantes de odontologia da Unicatólica quanto a realização de atendimentos clínicos. Quixadá - CE, 2021.

\begin{tabular}{|c|c|c|}
\hline Questões & $\mathrm{n}$ & $\%$ \\
\hline \multicolumn{3}{|l|}{$\begin{array}{l}\text { 1.Você sente medo quando ouve que as pessoas estão morrendo por } \\
\text { causa do COVID-19? }\end{array}$} \\
\hline Sim & 151 & 90,4 \\
\hline Não & 8 & 4,8 \\
\hline Não sei & 8 & 4,8 \\
\hline \multicolumn{3}{|l|}{$\begin{array}{l}\text { 2. Você tem medo de levar a infecção da clínica odontológica para a } \\
\text { sua familia? }\end{array}$} \\
\hline Sim & 149 & 89,2 \\
\hline Não & 10 & 6,0 \\
\hline Não sei & 8 & 4,8 \\
\hline \multicolumn{3}{|l|}{$\begin{array}{l}\text { 3.Você se sente nervoso ao conversar com pacientes em ambientes } \\
\text { fechados? }\end{array}$} \\
\hline Sim & 58 & 34,7 \\
\hline Não & 92 & 55,1 \\
\hline Não sei & 17 & 10,2 \\
\hline \multicolumn{3}{|l|}{$\begin{array}{l}\text { 4.Você se sente ansioso em fornecer tratamento a um paciente que } \\
\text { está tossindo ou com suspeita de estar infectado com COVID-19? }\end{array}$} \\
\hline Sim & 134 & 80,2 \\
\hline Não & 16 & 9,6 \\
\hline Não sei & 17 & 10,2 \\
\hline \multicolumn{3}{|l|}{$\begin{array}{l}\text { 5. Você está com medo de se infectar com COVID-19 de um paciente } \\
\text { ou colega de sala? }\end{array}$} \\
\hline Sim & 133 & 79,6 \\
\hline Não & 22 & 13,2 \\
\hline Não sei & 12 & 7,2 \\
\hline \multicolumn{3}{|l|}{$\begin{array}{l}\text { 6. Você se sente inseguro quanto o retorno das atividades clínicas / } \\
\text { laboratoriais? }\end{array}$} \\
\hline Sim & 78 & 46,7 \\
\hline Não & 73 & 43,7 \\
\hline Não sei & 16 & 9,6 \\
\hline \multicolumn{3}{|l|}{ 7. Qual o principal motivo de sua insegurança? } \\
\hline $\begin{array}{r}\text { Contaminação } \\
\text { Transmissão para outras pessoas }\end{array}$ & $\begin{array}{l}52 \\
24\end{array}$ & $\begin{array}{l}68,4 \\
31,6\end{array}$ \\
\hline
\end{tabular}

Fonte: Autores. 
A média de pontos na Escala de Beck de Ansiedade foi de 18,84 ( $\pm 12,88)$, o que corresponde a uma ansiedade leve. Quando estratificados em percentuais, $61,1 \%$ dos alunos apresentaram sintomas mínimos/suaves e 38,9\% apresentaram sintomas moderados/severos. Conforme demostrado na Tabela 3, o sintoma menos sentido pelos alunos foram os desmaios (94,6\%), enquanto a sensação se insegurança foi o sintoma mais sentido de forma severa $(26,3 \%)$.

Tabela 3: Percentual de sintomas de ansiedade sentido pelos estudantes de odontologia da Unicatólica. Quixadá - CE, 2021.

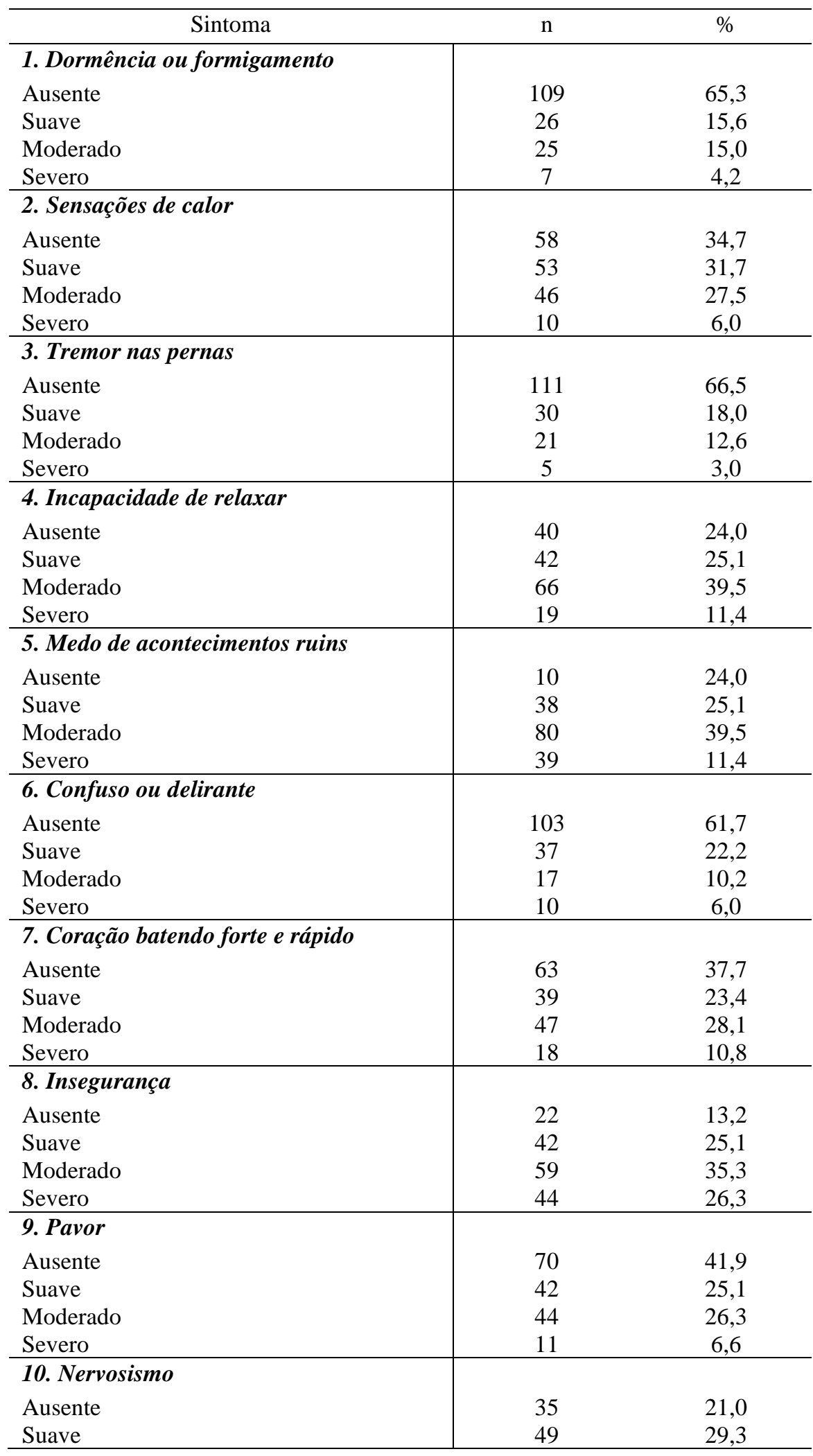


Research, Society and Development, v. 10, n. 8, e26010817171, 2021

(CC BY 4.0) | ISSN 2525-3409 | DOI: http://dx.doi.org/10.33448/rsd-v10i8.17171

\begin{tabular}{|c|c|c|}
\hline $\begin{array}{l}\text { Moderado } \\
\text { Severo }\end{array}$ & $\begin{array}{l}60 \\
23 \\
\end{array}$ & $\begin{array}{l}35,9 \\
13,8 \\
\end{array}$ \\
\hline \multicolumn{3}{|c|}{ 11. Sensação de sufocamento } \\
\hline Ausente & 97 & 58,1 \\
\hline Suave & 26 & 15,6 \\
\hline Moderado & 29 & 17,4 \\
\hline Severo & 15 & 9,0 \\
\hline \multicolumn{3}{|c|}{ 12. Tremor nas mãos } \\
\hline Ausente & 110 & 65,9 \\
\hline Suave & 26 & 15,6 \\
\hline Moderado & 22 & 13,2 \\
\hline Severo & 9 & 5,4 \\
\hline \multicolumn{3}{|c|}{ 13. Trêmulo (a) } \\
\hline Ausente & 121 & 72,5 \\
\hline Suave & 24 & 14,4 \\
\hline Moderado & 13 & 7,8 \\
\hline Severo & 9 & 5,4 \\
\hline \multicolumn{3}{|c|}{ 14. Medo de perder o controle } \\
\hline Ausente & 80 & 47,9 \\
\hline Suave & 37 & 22,2 \\
\hline Moderado & 36 & 21,6 \\
\hline Severo & 14 & 8,4 \\
\hline \multicolumn{3}{|c|}{ 15. Dificuldade de respirar } \\
\hline Ausente & 98 & 58,7 \\
\hline Suave & 28 & 16,8 \\
\hline Moderado & 31 & 18,6 \\
\hline Severo & 10 & 6,0 \\
\hline \multicolumn{3}{|c|}{ 16. Medo de morrer } \\
\hline Ausente & 54 & 32,3 \\
\hline Suave & 47 & 28,1 \\
\hline Moderado & 40 & 24,0 \\
\hline Severo & 26 & 15,6 \\
\hline \multicolumn{3}{|c|}{ 17. Assustado (a) } \\
\hline Ausente & 55 & 32,3 \\
\hline Suave & 50 & 28,1 \\
\hline Moderado & 46 & 24,0 \\
\hline Severo & 16 & 15,6 \\
\hline \multicolumn{3}{|c|}{ 18. Indigestão ou desconforto abdominal } \\
\hline Ausente & 55 & 32,9 \\
\hline Suave & 50 & 29,9 \\
\hline Moderado & 46 & 27,5 \\
\hline Severo & 16 & 9,6 \\
\hline \multicolumn{3}{|c|}{ 19. Desmaios } \\
\hline Ausente & 158 & 94,6 \\
\hline Suave & 2 & 1,2 \\
\hline Moderado & 7 & 4,2 \\
\hline Severo & 0 & 0 \\
\hline \multicolumn{3}{|c|}{ 20. Rubor facial } \\
\hline Ausente & 136 & 81,4 \\
\hline Suave & 17 & 10,2 \\
\hline Moderado & 12 & 7,2 \\
\hline Severo & 2 & 1,2 \\
\hline \multicolumn{3}{|c|}{ 21. Sudorese (não devido ao calor) } \\
\hline Ausente & 110 & 65,9 \\
\hline Suave & 26 & 15,6 \\
\hline Moderado & 23 & 13,8 \\
\hline Severo & 8 & 4,8 \\
\hline
\end{tabular}

Fonte: Autores. 
A Tabela 4 traz a associação entre as características sociodemográficas dos alunos com o nível de sensação dos sintomas de ansiedade. A única variável que apresentou associação estatística significante foi a presença de uma crença/religião, que esteve associada com a menor sensação dos sintomas de ansiedade ( $\mathrm{p}=0,039)$.

Tabela 4: Nível de sensação dos sintomas de ansiedade quanto às condições socioeconômicas de estudantes de odontologia da Unicatólica. Quixadá - CE, 2021.

\begin{tabular}{|c|c|c|c|c|c|c|}
\hline & \multicolumn{2}{|c|}{ Mínino / Leve } & \multicolumn{2}{|c|}{ Moderado / Grave } & \multirow[b]{2}{*}{ Pvalor } & \multirow[b]{2}{*}{$\boldsymbol{R P}$} \\
\hline & $n$ & $\%$ & $n$ & $\%$ & & \\
\hline \multicolumn{7}{|l|}{ Sexo } \\
\hline Feminino & 70 & 57,4 & 52 & 42,6 & 0,106 & $0,80(0,63-1,02)$ \\
\hline Masculino & 32 & 71,1 & 13 & 28,9 & & \\
\hline \multicolumn{7}{|l|}{ Autodeclaração de cor } \\
\hline Branca & 42 & 58,3 & 30 & 41,7 & 0,517 & $0,92(0,72-1,18)$ \\
\hline Negra & 60 & 63,2 & 35 & 36,8 & & \\
\hline \multicolumn{7}{|l|}{ Estado Civil } \\
\hline Casado / União Estável & 5 & 62,5 & 3 & 37,5 & 0,933 & $1,02(0,59-1,77)$ \\
\hline Solteiro & 97 & 61,0 & 62 & 39,0 & & \\
\hline \multicolumn{7}{|l|}{ Filhos } \\
\hline Sim & 4 & 57,1 & 3 & 42,9 & 0,827 & $1,07(0,55-2,06)$ \\
\hline Não & 98 & 61,3 & 62 & 38,8 & & \\
\hline \multicolumn{7}{|l|}{ Trabalha } \\
\hline Sim & 12 & 50,0 & 12 & 50,0 & 0,229 & $1,25(0,82-1,91)$ \\
\hline Não & 90 & 62,9 & 53 & 37,1 & & \\
\hline \multicolumn{7}{|l|}{ Renda } \\
\hline Até 2 Salários Mínimos & 42 & 61,8 & 26 & 38,2 & 0,880 & $1,01(0,79-1,30)$ \\
\hline Acima de 2 Salários Mínimos & 60 & 60,6 & 39 & 39,4 & & \\
\hline \multicolumn{7}{|l|}{ Religião } \\
\hline Sim & 94 & 63,9 & 53 & 36,1 & 0,039 & $1,66(1,09-2,52)$ \\
\hline Não & 8 & 40,0 & 12 & 60,0 & & \\
\hline
\end{tabular}

Fonte: Autores.

Já na Tabela 5, é possível observar a associação entre as variáveis de medo e insegurança com o nível de sensação dos sintomas de ansiedade. Foi possível identificar que a presença de sintomas mínimos / leves de ansiedade esteve associada com a ausência de medo quanto ao oferecimento de tratamento clínico para um paciente com tosse ou suspeita de COVID-19 ( $\mathrm{p}=0,003)$; ausência de medo de contágio por COVID-19 ( $\mathrm{p}=0,008)$; ausência de insegurança quanto ao retorno das atividades clínicas e laboratoriais $(\mathrm{p}=0,008)$. 
Tabela 5: Nível de sensação dos sintomas de ansiedade quanto às questões de medo e insegurança em estudantes de odontologia da Unicatólica. Quixadá - CE, 2021.

\begin{tabular}{|c|c|c|c|c|c|c|}
\hline \multirow[t]{2}{*}{ Questões } & \multicolumn{2}{|c|}{ Mínino / Leve } & \multicolumn{2}{|c|}{$\begin{array}{c}\text { Moderado / } \\
\text { Grave }\end{array}$} & \multirow[b]{2}{*}{ P valor } & \multirow[b]{2}{*}{$\boldsymbol{R P}$} \\
\hline & $n$ & $\%$ & $n$ & $\%$ & & \\
\hline \multicolumn{7}{|l|}{$\begin{array}{l}\text { 1. Você sente medo quando ouve que as pessoas } \\
\text { estão morrendo por causa do COVID-19? }\end{array}$} \\
\hline Sim & 91 & 60,3 & 60 & 39,7 & 0,900 & $0,94(0,55-1,67)$ \\
\hline Não & 5 & 62,5 & 3 & 37,5 & & \\
\hline \multicolumn{7}{|l|}{$\begin{array}{l}\text { 2. Você tem medo de levar a infecção da } \\
\text { clínica odontológica para a sua família? }\end{array}$} \\
\hline Sim & 90 & 60,4 & 59 & 30,6 & 0,217 & $0,75(0,54-1,05)$ \\
\hline Não & 8 & 80,0 & 2 & 20,0 & & \\
\hline \multicolumn{7}{|l|}{$\begin{array}{l}\text { 3. Você se sente nervoso ao conversar com } \\
\text { pacientes em ambientes fechados? }\end{array}$} \\
\hline Sim & 31 & 53,4 & 27 & 46,6 & 0,064 & $0,78(0,53-1,03)$ \\
\hline Não & 63 & 68,5 & 29 & 31,5 & & \\
\hline \multicolumn{7}{|l|}{$\begin{array}{l}\text { 4. Você se sente ansioso em fornecer tratamento } \\
\text { a um paciente que está tossindo ou com } \\
\text { suspeita de estar infectado com COVID-19? }\end{array}$} \\
\hline Sim & 73 & 54,5 & 61 & 45,5 & 0,003 & $0,58(0,47-0,71)$ \\
\hline Não & 15 & 93,8 & 1 & 6,2 & & \\
\hline \multicolumn{7}{|l|}{$\begin{array}{l}\text { 5.Você está com medo de se infectar com } \\
\text { COVID-19 de um paciente ou colega de sala? }\end{array}$} \\
\hline Sim & 75 & 56,4 & 58 & 43,6 & 0,008 & $0,65(0,52-0,81)$ \\
\hline Não & 19 & 86,4 & 3 & 13,6 & & \\
\hline \multicolumn{7}{|l|}{$\begin{array}{l}\text { 6. Você se sente inseguro quanto o retorno das } \\
\text { atividades clínicas / laboratoriais? }\end{array}$} \\
\hline Sim & 39 & 50,0 & 39 & 50,0 & 0,008 & $0,70(0,53-0,91)$ \\
\hline Não & 52 & 71,2 & 21 & 28,8 & & \\
\hline
\end{tabular}

Fonte: Autores.

\section{Discussão}

Em meio à pandemia da COVID-19, decretada como estado pandêmico pela OMS em 11 de março de 2020, o ensino odontológico é caracterizado como desafiador, visto que a prática odontológica envolve procedimentos geradores de aerossóis (micropartículas de secreção respiratória transportadas pelo ar) (Meng et al., 2020). Em virtude disso, são necessários cuidados especiais com a saúde dos discentes, docentes, pacientes e colaboradores das instituições de ensino superior (IES), bem como medidas preventivas, tais como o distanciamento social. Nesse contexto, os estudantes de odontologia precisaram se adequar à um novo processo de ensino-aprendizagem por meio de atividades remotas, sem a realização de atividades práticas, o que pode proporcionar sentimentos de incerteza, ansiedade e estresse nos estudantes universitários (Sahu, 2020).

O presente estudo foi realizado de março a abril de 2021, período em que a Instituição de Ensino Superior (IES) alvo deste ensaio, encontrava-se com proibição da realização de atividades práticas na clínica odontológica de ensino devido ao decreto do estado do Ceará, de 12 de março de 2021 com n $\mathrm{n}^{\mathrm{o}}$ 33.980, que ampliou o isolamento social rígido para todos os municípios cearenses como medida necessária ao enfrentamento à COVID-19 em decorrência dos altos indicadores epidemiológicos ocasionados pela segunda onda da pandemia no Brasil.

No presente estudo, pode-se observar que a maioria dos discentes $(90,9 \%)$ afirmaram sentir medo ao escutar que as pessoas estão morrendo por COVID-19, o que pode deve ser reflexo aos altos números de óbitos no estado do Ceará no 
período de coleta. Segundo o boletim epidemiológico nº19 da secretaria de saúde do governo estadual, 9.169 óbitos confirmados, com uma taxa de letalidade de 2,3\% em decorrência da COVID-19, considerando apenas o período de janeiro de 2021 a 15 de maio de 2021 (Ceará, 2021). Assim, a situação calamitosa do estado com altos números de óbitos confirmados pode ter contribuído para a sensação de medo entre os estudantes.

Adicionalmente a isto, aproximadamente a metade da amostra demonstrou insegurança quanto ao retorno das atividades práticas clínicas, assim como a maioria associou esta insegurança ao medo do contágio da COVID-19. O aumento exponencial de casos no Ceará, bem como às recorrentes notícias de aumento de óbitos em Quixadá, município da IES, podem também estar relacionados a essa sensação de insegurança quanto ao retorno das atividades práticas. Além disso, a insegurança causada pelo medo de contágio se explica pelas características inerentes a própria prática odontológica como: a proximidade face-a-face com os pacientes durante a realização dos procedimentos; o contato com fluidos corporais que possam estar potencialmente contaminados; a permanência do vírus no ambiente e material odontológico; e a produção de aerossóis na maioria dos procedimentos odontológicos, que contribuem com o maior risco da profissão em tempos de pandemia de COVID-19 (Franco et al., 2020; Peng et al., 2020).

Mais da metade dos acadêmicos $(89,2 \%)$ relatou possuir medo de levar a infecção pelo novo coronavírus para seus familiares, o que corrobora com as evidências explanadas por Ayanian (2020), que enfatizou diversos fatores que estão contribuindo para o sofrimento psicológico de profissionais da saúde que prestam atendimento à pacientes acometidos pela COVID-19, e dentre eles, destaca-se a preocupação em contaminar membros familiares, e especialmente os mais velhos, imunocomprometidos ou que sejam portadores de doenças crônicas.

Cerca de dois terços dos discentes também afirmaram sentirem medo de serem infectados através de um paciente ou colega de turma, o que é relatado por Adams \& Walls (2020) como um dos principais problemas de saúde que afeta os profissionais envolvidos no cuidado de pacientes em meio à pandemia da COVID-19, evidenciando que na China, país pioneiro no diagnóstico de casos da doença, cerca de 3.300 trabalhadores da saúde foram contaminados e 22 foram a óbito. Ademais, de maneira mais específica em relação ao território brasileiro, segundo o Ministério da Saúde em 2021, até o dia 17 de maio foram confirmados 96.215 casos de COVID-19 em profissionais de saúde, e ainda, foram hospitalizados 1.187 profissionais desta categoria com síndrome respiratória aguda grave em decorrência da COVID-19 (Brasil, 2021).

Já em relação à ansiedade, os dados obtidos neste estudo demonstraram que os participantes apresentam uma ansiedade leve, considerando a média de pontos na Escala de Beck de Ansiedade, o que vai ao encontro dos achados de Maia \& Dias (2020), que revelaram um aumento da ansiedade em estudantes universitários durante o período pandêmico. Além disso, ressalta-se que 46,7\% da amostra mostrou-se insegura em relação ao retorno às atividades práticas, e associado a isto, cerca de um terço da amostra relata insegurança de forma severa, corroborando com os estudos de Maia \& Dias (2020).

Indo de encontro ao estudo de Silva e colaboradores (2021), em que se observou maior prevalência da ansiedade em profissionais do sexo feminino e que apresentavam doenças crônicas. Entretanto, no presente estudo verificou-se apenas uma associação estatística significante com a presença de crença/religião, estando então associada à menor sensação dos sintomas de ansiedade. Esses achados corroboram com as elucidações de Teixeira e colaboradores (2021), em que ao analisarem estudantes de IESs públicas e privadas, dentre elas a Unicatólica, constatou-se uma associação entre possuir religião e estar satisfeito com a qualidade de vida durante a pandemia, o que evidencia a crença de que o período pandêmico é passageiro e de que a fé em algo divino os dará proteção pode ser uma razão crucial para o menor sentimento de ansiedade (Murakami \& Campos, 2012).

Não obstante, percebeu-se ainda que a presença de sintomas mínimos/leves de ansiedade estava associada com a ausência de medo no atendimento de um paciente com tosse ou suspeita de COVID-19, sugerindo assim que, mesmo se sentindo inseguros, os discentes confiam nas novas medidas adotadas durante a pandemia para o atendimento odontológico, 
tais como: atendimento com horário marcado, higienização frequente do ambiente clínico, minimização da realização de procedimentos geradores de aerossóis, aferição constante de temperatura do paciente e dos acadêmicos (Costa et al., 2020; Estellita et al., 2020; Franco et al., 2020).

Adicionalmente a isto, ainda foi possível verificar que a presença de sintomas mínimos/leves de ansiedades esteve associada à ausência de medo de contágio por COVID-19 e à ausência de insegurança quanto ao retorno das atividades clínicas e laboratoriais, o que pode estar relacionado ao conhecimento dos discentes acerca de todos os protocolos de biossegurança adotados frente ao período pandêmico vivenciado, evidenciando a correta utilização dos equipamentos de proteção individual (EPI), além de protocolos básicos de higiene pessoal e limpeza e armazenamento dos EPI (Machado et al., 2020; Santos \& Barbosa, 2020). Complementarmente, acreditamos que o anseio pela formatura pode sobrepor a sensação de insegurança nesses acadêmicos, que certamente vislumbram um futuro promissor no mercado de trabalho, visando estabilidade financeira $\mathrm{e}$ pessoal.

Diante disso, uma das principais limitações deste estudo trata-se do desenho transversal que não permite uma identificação direta de fatores causais. Portanto, futuros estudos com delineamento longitudinal serão importantes para melhor estabelecer os fatores causais, assim como o risco para o desenvolvimento de medo e ansiedade no contexto aqui avaliado. Outra limitação trata-se da avaliação do medo e ansiedade destes acadêmicos apenas no período pandêmico, não havendo uma análise em um período considerado normal para efeito de comparação. Além do mais, assim como em outros estudos que dependem da recordação dos pacientes, este estudo também está sujeito ao viés de memória dos entrevistados.

Por se tratar da realidade de apenas uma instituição, certas generalizações devem ser vistas com cautela para se evitar equívocos. Entretanto, este estudo é um ponto de partida para que possamos compreender os impactos da pandemia da COVID-19 na saúde mental dos discentes de odontologia. Acredita-se que estes resultados possam ser utilizados para melhor compreender essa nova realidade e os impactos dela na saúde mental dos estudantes, além de poderem ser usados para desenvolver ações que possam contribuir na manutenção da qualidade de vida deles. Assim, este estudo demonstra, através dos seus resultados, a necessidade de estar-se atento aos efeitos psicológicos desta pandemia em estudantes de odontologia.

\section{Conclusão}

Por fim, através dos dados encontrados com este estudo, pode-se concluir que a maioria dos discentes avaliados apresentou sintomas mínimos/leves de ansiedade, o que se apresentou de forma associada à um menor medo e insegurança na realização das atividades clínicas na universidade, além da presença de uma crença ou religião.

\section{Referências}

Adams, J. G., \& Walls, R. M. (2020). Supporting the health care workforce during the COVID-19 global epidemic. Jama, 323(15), 1439-1440

Ataş, O. \& Talo-Yildirim, T. (2020). Evaluation of knowledge, attitudes, and clinical education of dental students about COVID-19 pandemic. Peer J. 8 , e9575.

Ayanian, J. Z. (2020). Necessidades de saúde mental dos profissionais de saúde que prestam cuidados de primeira linha COVID-19. JAMA Health Forum. 1(4), e200397.

Beck, A. T., Epstein, N., Brown, G., \& Steer, R. A. (1988). An inventory for measuring clinical anxiety: Psychometric properties. Journal of Consulting and Clinical Psychology. 56, 893-897.

Brasil. (2021). Ministério da Saúde. Boletim COVID-19.

Ceará. Secretaria da Saúde. Doença pelo novo Coronavírus - Boletim No 19. Ceará, 2021.

Cunha, J. A. (2001). Manual da versão em português das Escalas Beck. Casa do Psicólogo.

da Costa, J. C. R., Martins, M. A. S., \& Rodrigues, L. V. (2020). O cuidado no atendimento às crianças no consultório odontológico frente à pandemia da COVID-19. Arquivos em Odontologia, 56 
Research, Society and Development, v. 10, n. 8, e26010817171, 2021

(CC BY 4.0) | ISSN 2525-3409 | DOI: http://dx.doi.org/10.33448/rsd-v10i8.17171

de Almeida, R. Z., Casarin, M., Freitas, B. O. \& Muniz, F. W. M. G. (2020). Medo e ansiedade de estudantes de Odontologia diante da pandemia do novo coronavírus: um estudo transversal. Archives of Health Investigation. 9(6)9, 623-628.

dos Santos, K. F., \& Barbosa, M. (2020). COVID-19 e a Odontologia na prática atual. Revista Eletrônica Acervo Saúde, 12(11), e5113-e5113

Estellita, M. C. A., Pascoal, S. C. D., Lima, K. E. R., da Cunha Queiroz, E., \& Mendes, T. A. D. (2020). Análise do coronavírus SARS-CoV-2/COVID-19 no cenário atual da pandemia mundial: revisão de literatura/Analysis of the coronavirus SARS-CoV-2/COVID-19 in the current world pandemic scenario: literature review. Brazilian Journal of Health Review, 3(3), 7058-7072

JB, F., De Camargo, A. R., \& MPSM, P. (2020). Cuidados Odontológicos na era do COVID-19: recomendações para procedimentos odontológicos e profissionais. Rev Assoc Paul Cir Dent, 74(1), 18-21.

Lu, R., Zhao, X., Li, J., Niu, P., Yang, B., Wu, H., \& Tan, W. (2020). Genomic characterisation and epidemiology of 2019 novel coronavirus: implications for virus origins and receptor binding. The lancet, 395(10224), 565-574.

Machado, G. M., Kasper, R. H., Busato, A. L. S., \& Vinholes, J. (2020). Biossegurança e retorno das atividades em odontologia: aspectos relevantes para enfrentamento de covid-19. STOMATOS, 26(50)

Maia, B. R., \& Dias, P. C. (2020). Ansiedade, depressão e estresse em estudantes universitários: o impacto da COVID-19. Estudos de Psicologia (Campinas), 37

Meng, L., Hua, F., \& Bian, Z. (2020). Coronavirus disease 2019 (COVID-19): emerging and future challenges for dental and oral medicine. Journal of dental research, 99(5), 481-487.

Murakami, R., \& Campos, C. J. G. (2012). Religião e saúde mental: desafio de integrar a religiosidade ao cuidado com o paciente. Revista Brasileira de Enfermagem, 65(2), 361-367.

Peng, X., Xu, X., Li, Y., Cheng, L., Zhou, X., \& Ren, B. (2020). Transmission routes of 2019-nCoV and controls in dental practice. International journal of oral science, 12(1), 1-6.

Prado, A. D., Peixoto, B. C., Silva, A. M. B. \& Scalia L. A. M. (2020). A saúde mental dos profissionais de saúde frente à pandemia do COVID-19: uma revisão integrativa. Revista Eletrônica Acervo Saúde. 46, e4128-e4128

Sahu, P. (2020). Closure of Universities Due to Coronavirus Disease 2019 (COVID-19): Impact on Education and Mental Health of Students and Academic Staff. Cureus. 12(4), e7541.

Silva, D. F. O., Cobucci, R. N., Soares-Rachetti, V. D. P., Lima, S. C. V. C., \& Andrade, F. B. D. (2021). Prevalência de ansiedade em profissionais da saúde em tempos de COVID-19: revisão sistemática com metanálise. Ciência \& Saúde Coletiva, 26, 693-710.

Teixeira, C. N. G., de Queiroz Rodrigues, M. I., da Silva, R. A. D. A., Silva, P. G. B., \& Barros, M. M. A. F. (2021). Qualidade de vida em estudantes de odontologia na Pandemia de COVID-19: um estudo multicêntrico. Saúde e Pesquisa, 14(2).

Velavan, T. P. \& Meyer, C, G. (2020). The COVID-19 epidemic. Medicina tropical e saúde internacional. 25(3), 278.

Xu, H., Zhong, L., Deng, J., Peng, J., Dan, H., Zeng, X., Li, T. \& Chen, Q. (2020). High expression of ACE2 receptor of 2019-nCoV on the epithelial cells of oral mucosa. Int Oral Sci. 12(1), 1-5.

Zhang, Y., \& Ma, Z. F. (2020). Impact of the COVID-19 pandemic on mental health and quality of life among local residents in Liaoning Province, China: A cross-sectional study. International journal of environmental research and public health, 17(7), 2381. 